\title{
Time Frames
}

for

Geothermal Project Development

By

David W. McClain

President DW McClain \& Associates

Pacific Northwest Geothermal Resource Council Section Short Coarse Presentation

April 17, 2001 


\section{DISCLAIMER}

This report was prepared as an account of work sponsored by an agency of the United States Government. Neither the United States Government nor any agency Thereof, nor any of their employees, makes any warranty, express or implied, or assumes any legal liability or responsibility for the accuracy, completeness, or usefulness of any information, apparatus, product, or process disclosed, or represents that its use would not infringe privately owned rights. Reference herein to any specific commercial product, process, or service by trade name, trademark, manufacturer, or otherwise does not necessarily constitute or imply its endorsement, recommendation, or favoring by the United States Government or any agency thereof. The views and opinions of authors expressed herein do not necessarily state or reflect those of the United States Government or any agency thereof. 


\section{DISCLAIMER}

Portions of this document may be illegible in electronic image products. Images are produced from the best available original document. 


\section{Introduction}

\section{Phases of Development}

- Geothermal development can generally be broken down into distinct phases:

- Exploration and Leasing

- Project Development And Feasibility Studies

- Well Field Development

- Project Finance, Construction and Start-up Operations

- Commercial Operations 
- Each phase represent different levels of cost and risk and different types of management teams that are needed to assess and manage the project and associated risk. Orderly transitions of management at each major phase are needed.

- Exploration programs are largely science based, the primary focus of the science based investigations should be to:

o secure the lease position, and

- develop sufficient information to identify and characterize an economical geothermal resource.

- Project development specialists build on the exploration data to:

- pull together a project design,

- develop a detailed cost estimate

- prepare an environmental assessment

- collect all data needed for project financing.

- Construction specialist build from the development phase to

o develop detailed engineering,

- procure equipment and materials and

- schedule and manage the facilities construction programs, and

o start and test the power plant.

- Operations specialists take over from construction during start-up and are responsible for sustainable and reliable operations of the resource and power generation equipment over the life of the project 


\section{Exploration and Leasing Phase}

The exploration and leasing phase of a geothermal project involves

- assessing the resource and the securing of the rights to access the land area and develop the resource.

This phase involves three progressively more complex steps:

- Reconnaissance resource assessment

- Leasing and land acquisition and restrictions assessment

- Exploration drilling and well testing

Typically 2 to 5 years

1 to 2 years for environmental work for leasing

1 to 2 years for exploration work

In some areas this phase takes less than 2 years if

- prior completion of environmental assessments

- prior geological information to site wells 


\section{Reconnaissance Resource Assessment}

The risk of development decreases with increased knowledge of the reservoir conditions.

- In order to make an informed assessment of a resource area, the following types of information must be collected and evaluated:

- Reconnaissance geology and field reports

- Lithological descriptions

- Regional hydrology and other related regional geological field reports

- Hot springs and fumarole physical descriptions

- Regional and local fault locations

- Geology and geophysics maps and cross sections

- Inventory of existing wells

- Well logs

- Productivity test data

- Seismic data

- Remote Serising data

- Geochemistry of hot springs and wells

- Down hole geophysical surveys

- Slim hole drilling and heat flow studies 


\section{Leasing and Risk Assessment}

The leasing task will involve the following milestones:

- Securing a lease / franchise agreement / or purchase agreement.

- Negotiating lease terms, which are favorable and provide the right to access and develop the land including any roads and transmission line rights of way.

- Defining the lease period and renewal options.

- Defining the royalty and rental payments.

- Defining the bond requirements for reclamation and other insurance terms.

- Defining any restrictions to the use of the land that increase risk.

Risk Assessment will include assessing the project areas conditions and constraints for:

- governmental,

- institutional and

- environmental conditions and constraints.

- areas with sensitive environmental conditions, such as:

- near by communities,

- sensitive habitat areas,

- water-shed resources, and

- recreation facilities

Mitigation which will increase cost.

Environmental conditions may also restrict the area of operations and the season of operation, which will also increase the risk of development.

The early assessment of environmental and institutional risk are an essential part of any geothermal resource site assessment. 


\section{Exploration Drilling and Reservoir Assessment}

The exploration drilling phase of the project has the highest risk of all phase and usually involves the following general task:

- Geophysical surveys

- Slim Hole drilling and heat flow measurements

- Slim hole reservoir confirmation well drilling

- Exploration well drilling and reservoir production testing

- Environmental and regulatory approvals for drilling

- Environmental baseline data collection

- The exploration drilling phase involves a significant increase in cost and risk.

- The nature of the work will involve regulatory approvals, detailed geological assessments, drilling management, and reservoir evaluation.

- The nature of the project management team changes to manage the details and cost of a more intensive and costly exploration program.

- The project manager should be an experienced manager who is familiar with the high risk and interpretive nature of geological exploration.

Risk management, data evaluations, and cost control becomes the dominant theme of the management team.

Scheduling and integration of task becomes more important as timely completion of sequential task are needed to have a successful exploration program. 
In general the following series of task need to be completed for each well drilled during the exploration program:

- Compile all geological data.

- Determine what additional geological surveys are needed to site exploration. wells, this usually involves some additional geophysical studies.

- Identify prospective well pad locations required to drill up prospective targets.

- Develop an adequate topographic map for the well locations.

- Design the well location and road cut and fill requirements.

- Obtain regulatory approvals for the well locations.

- Develop a water resources to support the drilling and construction.

- Build the access roads and well locations.

- Mobilize a drilling rig to the site and assemble the rig.

- Drill the well to the targeted depth.

- Evaluate the geological data while drilling.

- Log the completed well.

- Rig test the well for production flow and if necessary set casing or deepen.

- Demobilize the drill rig to another location or stack it on site.

- Assemble a well test equipment.

- Flow test the well for 15 to $\mathbf{4 5}$ days.

- Collect reservoir data on flow rates, pressure and chemistry.

- Collect environmental data related to all of these activities.

Exploration Deliverable:

- In order to complete the type of reservoir tests that are usually required for institutional financing, drilling and testing of at least two to three production wells and one injection well are necessary to compile sufficient reservoir data to build a representative production model of the reservoir.

- All geological data and well testing data are then summarized into a Reservoir Assessment Report, which can be used to support institutional financing.

- An assessment of all environmental, regulatory and institutional constraints should be prepared for the financial institutions. 


\section{Cost}

Cost for the exploration activities range from $\$ 750,000$ to $\$ 2,500,000$ per well.

- Slim holes and core holes to 5,000 feet depth - cost between $\$ 350,000$ to $\$ 750,000$ per well

- Production test wells to 5,000 feet depth - Cost between $\$ 1,200,000$ to $\$ 2,500,000$ per well

Exploration programs generally require between $\$ 3,000,000$ to $\$ 9,000,000$ to complete:

- geophysical programs

- drilling of several slim holes and temperature gradient core holes.

- to complete and well testing at least 3 production wells

- to complete and test at least 1 injection well.

Commercial banks are extremely reluctant to finance this stage of work.

Therefore private developers must raise funds either internally or from additional investors. In some areas, local governments may fund exploration activities. 
Schedule:

Exploration Drilling takes between 2 and 5 years to complete

Reconnaissance: 4 months to 1 year

Permitting 6 months to 1 year

Slim holes and geophysics: 6 months to 1 year

Deep Exploration Drilling and Testing of 3 to

4 wells: 1 to 2 years

Well Drilling and Test Each Well:

Slim Holes to 4,000 feet: 60 days

Pad Construction: 2 days

Mobilization and assemble: 3 days

Drilling to 4,000 feet: 50 days

Logging and Testing: 5 days

Demobilization: 2 days

Exploration Test Wells to 8,000 feet:

Pad Construction 1 to 2 weeks

Mobilization and rig assemble: 1 to 2 weeks

Drilling: $6-8$ weeks

Rig Test: 2 days

Demobilization: 5 days

Flow Test: 15 to $\mathbf{4 5}$ days 


\section{Project Development And Feasibility Phase}

Introduction

- The development phase is the critical step between exploration and construction of a geothermal project.

- During this phase the developer is working to:

- obtain a power sales contract,

- complete any environmental studies,

- obtain regulatory approvals and key pre-construction permits,

- define the project capital cost, develop a detailed economic Performa model of the project and obtain financing for the construction.

Getting a project to the point where construction can begin involves a number of critical task with the following four task being the core objectives of any project:

- Completion of a reservoir assessment report.

- Obtaining a power sales contract for sale of the power output.

- Obtaining all pre-construction environmental approvals.

- Completing a preliminary design and cost estimate.

When a project has achieved these milestones, a project finance package can usually be completed.

Obtaining project financing is often considered

- the final milestone of the Project Development Phase or

- The first task of the Construction Phase. 


\section{Reservoir Assessment Report}

What makes a geothermal development project different?

- It has all the same risk elements of other power projects

- Except it is the dependence upon a site specific reservoir.

The unique aspect in determining the feasibility of a geothermal project is defining the geothermal resource itself.

The reservoir assessment report is the critical path document for project finance:

- documents the resource discovery

- documents reservoir testing data and

- provides assurances that the resource will sustain the planned power plant.

The Key deliverables is the reservoir assessment report

- prepared by a third party reservoir engineer

- who is acceptable to the lending institutions or

- is the lending institution's own reservoir engineering consultant. 


\section{Power Sales Contract}

The critical path task for the development phase is obtaining a power sales contract.

The primary team members who are working on this task are the project manger and the legal council.

The sales agreement will define the following economic parameters:

-Power purchase price

-Maximum amount of power to be sold

- Minimum amount of power to be sold

- Contract term (number of years)

-Wheeling or transmission charges

-Penalties for non-performance

-Delivery criteria, voltage control and other technical parameters

This is only a partial list of provisions that are found in a power sales agreement and a standard agreement contains many more provision, terms and conditions for performance, default and delivery.

The economic parameters in the power sales agreement establish the revenue stream for the project and thus dictate the economic feasibility of the project.

The power sales agreement is considered the single most important key deliverable of this phase of the project, without which a project would not be feasible. 


\section{Preliminary Design, Cost Estimate and Feasibility Analysis}

Well field development plan and cost estimate:

- Uses the reservoir assessment report as basis,

- Identifies the location of additional well pads and the number of additional wells that are needed to sustain the power plant.

- Uses the reservoir productivity data and

- All of the environmental, geotechnical and resource data collected in the exploration phase is used to prepare preliminary design criteria, cost estimates and a project feasibility analysis.

- The project engineering consultant prepares a detailed design of the process flow, which defines the parameters for the heat and material balance of the power plant design.

- The project feasibility analysis is also a key deliverable because it will be used to justify continuation of the project and in securing financing.

The preliminary design that is developed can then be used to establish procurement specifications for major equipment and a general layout of the equipment arrangement.

The probable interconnection point for the transmission line must also be defined at this point in order to estimate the transmission line capital cost.

Environmental criteria such as air quality standards are also defined in terms of engineering specifications.

A project capital cost estimate can then be built from this information and generally will include:

- An estimate of the well field development cost based on the exploration

\%. wells cost.

- An estimate the pipeline construction cost based on the well field development plan and the location of additional production and injection wells and the need for separators in the well field.

- An estimate of the transmission line cost based on the line size, type of construction and distance to the interconnection point.

- An estimate of the installed cost of the power plant based on preliminary design configuration and any specific regulatory criteria regarding air and water discharges.

- An estimate of the environmental and regulatory approval cost based on the work completed during the exploration phase. 


\section{Pre-construction Permits and Environmental Approvals}

Environmental and regulatory requirements vary by jurisdiction, national criteria and types of ownership.

Bank financing generally requires proof that the project has obtained or is capable of obtaining all necessary pre-construction regulatory approvals prior to the lending of funds

In the United States, on federal lands, an Environmental Impact Statement is required. This is a detailed study which generally takes two years to complete. In this case the environmental studies are started during the exploration phase and the Environmental Impact Statement is completed in the development phase.

Project permits such as air discharge and water discharge permits generally require detailed information regarding the power plant and well field layout and process parameters and often establish design criteria:

- Regulatory agencies set criteria for emissions and these standards become design criteria.

- Project site environmental issues also become design criteria, particularty when sensitive year or time of day when drilling and construction work can be accomplished.

- Environmental issues may require avoidance of an area by project facilities which may constrain the project layout.

- Environmental conditions or restrictions can also constrain the construction season.

- Institutional delays and poorly defined environmental criteria are often the primary source of most design and schedule conflicts during this phase of project development.

- Obtaining all the pre-construction regulatory approvals is a key deliverable of this phase of the project. Institutional financing is often held up until the key regulatory approvals have been obtained. 
Cost

The cost of this phase of development will vary by project location but will generally fall within the following ranges:

- Reservoir Assessment Report: $\mathbf{\$ 5 0 , 0 0 0 - \$ 1 5 0 , 0 0 0}$

- Power Sales Agreement Negotiation: $\$ \mathbf{2 5 , 0 0 0 - \$ 1 5 0 , 0 0 0}$

- Preliminary Design, Cost Estimate and Feasibility Analysis. \$50,000-\$100,000

- Pre-construction Permits and Environmental Approvals: $\mathbf{\$ 2 5 0 , 0 0 0 - \$ 2 , 0 0 0 , 0 0 0 0}$

Schedule:

Project Development Stage Takes 2 to 4 years to complete.

The most time consuming elements are the environmental and permitting factors because they usually have ridged time frames for review and approval which extend the schedule. $x$

Critical Path schedules usually place the permitting as the priority task. This is the lowest cost element but highest risk elements on the schedule. 


\section{Well Field Development}

The well field development phase is an intermediate phase, which often overlaps with the construction phase and takes place after key permits have been obtained.

- The primary focus of the well field development work is to develop sufficient commercial grade resource at the well head to satisfy power plant's daily steam requirements including resource reserves that are needed to meet bank finance requirements.

Well field development is an extension of the exploration program with many of the same management team members and similar types of technical problems

The Key Deliverable is to drill and test enough wells to have adequate well head capability to deliver full steam load requirements at power plant daring start up.

Early completion of this phase, prior to start of construction:

- lowers the risk profile of the project significantly

- shifts the risk profile from the developer to the engineer, procure, construct contractor (EPC contractor)

- risk profile becomes focused on design, construction and performance of the power plant.

Initiation of this phase is often delayed by the need to complete additional environmental studies and additional exploration test wells.

Well field development should not start until:

- there has been adequate exploration wells drilled and tested, and

- a favorable reservoir assessment report and project economic feasibility study have been completed.

- a favorable environmental approval has been granted. 


\section{Drilling Program}

If the feasibility study is favorable and the various risk elements are considered acceptable to the financier(s), the well field development work effort can occur in parallel with the engineering procurement and construction phase.

Well field development can be a several year work effort 24 to 36 month while construction of the power plant is often a much shorter 12 to 14 month effort. Therefore the start of construction is often delayed to allow the wellfield to be adequately developed.

The risk of the project shifts toward the construction elements with each successful well completion.

As a general rule, financial institutions are reluctant to loan money for well field development until the drilling program has:

1. proven at least $50 \%$ of the reserves,

2. the developer has invested at least $10 \%$ to $25 \%$ of the equity in the total project cost, and

3. the banks reservoir engineer has confirmed that there is sufficient heat flow and productivity to sustain the reservoir productivity and power plant output for the term of the loan.

Drilling with multiple drill rigs will reduce the time of well field development but this approach will increase risk and project management difficulty.

- A multiple rig drilling program essentially requires the drilling of some wells without the benefit of the results from prior wells to guide the drilling program.

- Using multiple drill rigs to develop the reservoir reserves requires a significant effort in staffing, data collection, data reduction and interpretation, procurement and delivery of drilling supplies.

- A multiple rig project can shorten the well field development schedule and therefore advance the construction schedule.

- There are some cost advantages that are possible through procurement and stockpiling of supplies such as drill bits, casing, mud, supplies. 
Cost

Well field development cost will vary by the type and depth of resource.

- Each production well will cost between $\$ 1,000,000$ to $\$ 2,500,000$ to complete

- Testing cost about $\$ 50,000$ to $\$ 150,000$ per well.

- A $50 \mathrm{MW}$ project will require the drilling of up to 16 wells prior to start-up based on the following parameters:

- 10 production (average $5 \mathrm{MW}$ per well)

- 2 dry holes (15\%)

- 2 production reserve wells (25\%)

- 2 injection wells

- Assuming an average well cost of $\$ 2,000,000$,

- Well field development share of the over all project cost would be $\$ 32,000,000$ for $50 \mathrm{MW}$

These are the highest risk investments in the project.

Management should make it a priority to place adequate and experienced manpower on these task to assure timely and economic completion of the work and technically accurate collection of all necessary analytical and interpretive data sets. 


\section{Schedule: Well Field Development}

Assume exploration drilling has completed 5 wells

3 wells are capable of production, one well capable of injection

and one junk and unusable.

Plant Start Up requires at least 10 wells at $5 \mathrm{MW}$ each and two injection wells.

A minimum of 12 additional successful completions are needed to meet the banks requirements for production injection and reserves.

Drilling program will involve two drilling rigs

- approximately 60 to 90 days per well.

- Well field development will take approximately 12 to 16 months to complete.

Risk Mitigation

Risk mitigation during well field development drilling is best accomplished through continuous evaluation of the geological and reservoir engineering data to improve the understanding of the subsurface drilling conditions, reservoir productivity and controlling permeability.

With each successful well the risk profile is shifting toward engineering and construction and away from resource risk. 
Reservoir Data Collection and Management

- Occurs in parallel with drilling and testing

- Data collection program becomes highly significant to the success of the project and the ability of the project to trigger financing.

- Many projects experience significant delays and unnecessary difficulties in closing financing because of either incomplete or inaccurate resource data.

- Forecasting reservoir and well field behavior is a continuous process, which starts with the first wells drilled and continues over the life of the project.

Project managers need to place additional emphasis on and support for the reservoir engineering team, as project should anticipate that this area would receive the greatest outside evaluation of the data, assumptions, and analytical forecast. 


\section{Project Finance And Construction Phase}

First major task of the management team is to prepare the engineer, procurement and construction (EPC) request for proposals

- The second major task is to select the EPC contractor and negotiate a contract including a detailed schedule which:

- commits the developer to completion of wells by start up

- commits the EPC contractor to time delivery of major equipment components

- commits the EPC to timely completion of the construction.

- includes substantial guarantees and equipment warranties.

Once the project has signed the EPC contract and completed a Reservoir Engineering Report, it can move rapidly to close project finance and initiate construction.

Delays at this point are usually attributed to problems with completion of resource definition task, environmental conditions and or regulatory approvals. 


\section{Construction Schedule}

Upon Award of EPC contract and completion of Financing

- 14 to 24 months from EPC award to Commercial Operations; Any where Western USA.

Plant Engineering and Design:

- 6 to 8 months

Equipment Procurement and Delivery:

- 14 to 24 months,

Starts about $2^{\text {nd }}$ month into engineering and continues through construction timed delivery as needed at site.

Long Lead Turbine Design and Fabrication:

- 12 to 14 months

Order is placed by $2^{\text {nd }}$ month of EPC to meet fast track Considered Critical Path of the EPC schedule.

Pipeline Engineering and Design:

- 3 to 5 months

Requires Developer to

pin point well head locations and well parameters.

Starts about $4^{\text {th }}$ month into plant engineering

Transmission Line Engineering and Design:

- 3 to 5 months

Requires approved ROW

Starts about $4^{\text {th }}$ month into plant engineering 
Civil Construction Power Plant Starts when Design and Engineering are $70 \%$ complete

- Site grading: 1 months

○ Install Underground Utilities: 2 months

- Prepare pads and Foundations: 4 months

- Erect Equipment Building: 2 months :

Piping and Mechanical Equipment Installation:

- 10 months

Starts 90 days prior to delivery of Turbine/Generator

Electrical and Control Equipment Installation:

- 10 months

Starts in parallel with Mechanical equipment installation

- Erect Cooling Tower:

60 days

Starts when CT basin piping and foundations completed

Construct Control Room and Admin. Building:

- 60 days

Starts in about $6^{\text {th }}$ month of Electrical Schedule

Transmission Construction and Tie-in:

- 4 to 6 months

Starts as soon as Transmission Design completed

Line completion should tie transformers delivery

Tie-in should occur as soon as completion to allow

Power back flow, at least 60 days prior to Start-up. 
Well Field Pipeline Construction:

- 4 to 6 months

Starts as soon as Design completed.

Construction timed to match well field drilling

Completed 60 days prior to start up.

Start up:

- 2 to 4 months

Equipment testing: 1 to 2 months

Starts when power back feed is available to test

equipment packages.

Heat Up of plant and separator testing; 1 month

Turbine role and testing:

1 hr test,

Synchronize unit to grid

24 hour test

30 day performance test

90 day capacity test

Commercial Operations 
The EPC contract places significant performance requirements on the contractor for:

- the detailed engineering design,

- equipment and materials procurement and

- timely completion of all specified construction.

- One single contractor, if capable, can be selected.

- has responsibility to subcontract more specialized task

- results in better coordination and

- timely interface of key components of the construction project.

- may not offer the lowest cost

- shift substantial risk to the EPC contractor

Multiple EPC contractors can be used to split the work:

- Requires the developer to manage multiple subcontractors

- Splits the work into packages:

- Site preparations and roads

- power plant construction,

- pipelines and separators,

- transmission line and substations 
A detailed work plan and schedule should be an attachment to the EPC contract. This plan will include at a minimum the following group of categories:

- Well field development schedule

- Detailed engineering schedule

- Procurement and purchasing schedule

- Field construction schedule

- Detalled work breakdown assignments

- Project controls

- Project organization

- Procedures and techniques

- Forms and paper flow

- Records mänagement

- Availability and quality of personnel

- Forecasting procedures

- Progress measurements techniques

- Critical milestones

- Critical interaction with engineering and field and developer

- Detailed Engineering Plan

- Design team organization

- Availability and quality of personnel

- Coordination of work functions

- Quality of drawings and specifications

- Use of models and computers

- Familiarity with design specifications

- Familiarity with applicable codes.

- Procurement and Purchasing

- Organization

- Procedures and techniques

- Forms and paper

- Knowledge of marketplace and vendors

- Guarantees and warranties on performance.

- Field Construction

- Management organization

- Safety awareness and procedures

- Field offices

- Availability and quality of personnel

- Labor force and knowledge of and use of local labor forces

- Mobilization and need for a camp

- Quality Control Procedures 
- Project and subcontractor organization

- Procedures and techniques

- Use of computers

- Forecasting procedures

- Reporting systems

- Timeliness of reports to the developer team and bank representatives

- Reporting and Communications

- Procedures between contractor and developer

- Procedures between contractor and vendors

- Interaction and communication between the engineering and construction teams

- Safety awareness and procedures 
Closing of EPC Finance

Closing of EPC finance package is usually required to finance the construction.

Some developers may start the engineering and procurement of long lead equipment prior to close of financial terms,

Developers will utilize some form of third part financing to complete the procurement of the power plant equipment and construction of the power plant.

The following task are generally required to close EPC finance:

- Acceptance of the reservoir report by the financial institution.

- Approval all pre-construction permits, environmental and regulatory requirements.

- Selection of EPC Contractor and negotiation of a fix price turnkey contract.

The closing of the EPC finance package is the key deliverable of this phase.

A project can often be financed when the developer has obtained the following

- a verifiable reservoir report and

- a power sales contract.

Obtaining favorable project finance is essentially a process of documenting to the lending institution's satisfaction that the project will have:

- a strong, predicable cash flow;

- has obtain all necessary authorization;

- has an adequate reservoir for steam supply; and

- has adequately identified and mitigated any risk associated with the project.

The ability to obtain favorable project finance is also a function of the quality of the contracts and the qualifications of the parties involved. The credentials of the developing parties, contractors and power purchasers are very important to the financial institutions.

Developers should expect a thorough auditing and evaluation of the project records. The project records should be organized such that the lending institution can evaluate each of the following elements:

- Geological and reservoir report

- Power sales agreements and transmission agreements 
- Environmental and institutional approvals and regulations

- Engineering design and cost estimate

- Equipment and technology selection

- Schedule for completion of drilling, procurement and construction

- Risk evaluation and mitigation plan

- Developer qualifications

- EPC Contractor qualifications

- Operations and maintenance plans 
Engineering, Procurement and Construction

- Construction is a field related activity,

- Design engineering and equipment procurement are completed well in advance of the construction.

- The EPC contractor should have good clear lines of communications between the field engineers and construction personnel and the engineering team to fix minor and major problems in a timely manner.

- Timing of delivery of procured equipment can often become a critical path if key equipment delivery is delayed.

- Project controls need to focus on maintaining scheduled milestones to complete the construction in a timely and organized manner. 


\section{WBS:}

The detailed work breakdown structure is needed to:

- define the developer's role

- identify critical task

- identify critical interface that are needed for the EPC contractor to complete the design and construction of the project.

- identify what the interfaces needed by the developer, particularly with respect to:

- design coordination with well field control systems

- construction work within the well field development area

- pipelines

- control values and separators

water supply for drilling and construction

well testing schedules.

Developers responsibilities:

- Completion of development drilling and well testing.

- Determining the number of wells needed to start-up.

- Reserve wells needed for finance requirements.

- Reservoir modeling.

- Supplying needed steam for start-up and testing.

- Installation of primary well head control valves.

- Removal of any drilling or testing equipment that may interfere with the EPC's construction activities.

- Providing adequate laydown area for the EPC contractor.

- Providing overall project site management and coordination between well field activities and EPC contractor activities. 
EPC contractor's responsibilities:

- Detailed engineering of all above ground facilities.

- Procurement of long lead equipment:

- Turbine generator

- Condenser

- Transformer

- Cooling tower

- Separators

Construction of all above ground facilities.

Maintaining an adequate trained labor force.

Maintain a labor camp if needed.

Maintaining the schedule milestones.

Engineering design review.

Critical path long lead equipment delivery.

Cost control and reporting.

Interfacing with leader representative.

Equipment installation and testing.

Start-up and testing of the power plant and pipeline system:

- Well start-up procedures

- Well control procedures

- Procedures for heat soak of the geothermal pipeline

- Procedures for heat soak of the power plant

- Equipment testing procedures

- Synchronization with the grid

- Operational testing

Supply all manuals and operating specifications 


\section{Start-up}

Start-up is the critical final task in the construction phase. Start-up involves three major steps:

- performance testing each piece of equipment

- individually tested for start and stop

- control system response

- power supply

- operations testing of all plant components

- circulating water systems and cooling tower

- emissions control systems

- power supply, transmission line back feed

- steam supply pipelines and separators.

- controls

- integrated operations and turbine role

- start all electrical systems

- heat sink the plant and start steam flow

- start circulating water operations

- turbine roll and power generation

A start-up plan is needed which delineates responsibilities and procedures between construction, start-up and operations teams.

- operations team is on site to assist in the start-up and to learn about the power plants various system components.

- Start-up is the responsibility of the EPC contractor.

- Close coordination is needed between the well field operators and the EPC contractor on well start-up procedures and environmental criteria for venting excess steam.

- During this period well flow and power output is variable depending on how smoothly the initial start-up and equipment testing are completed.

\section{Schedule:}

\section{2 to 4 months}




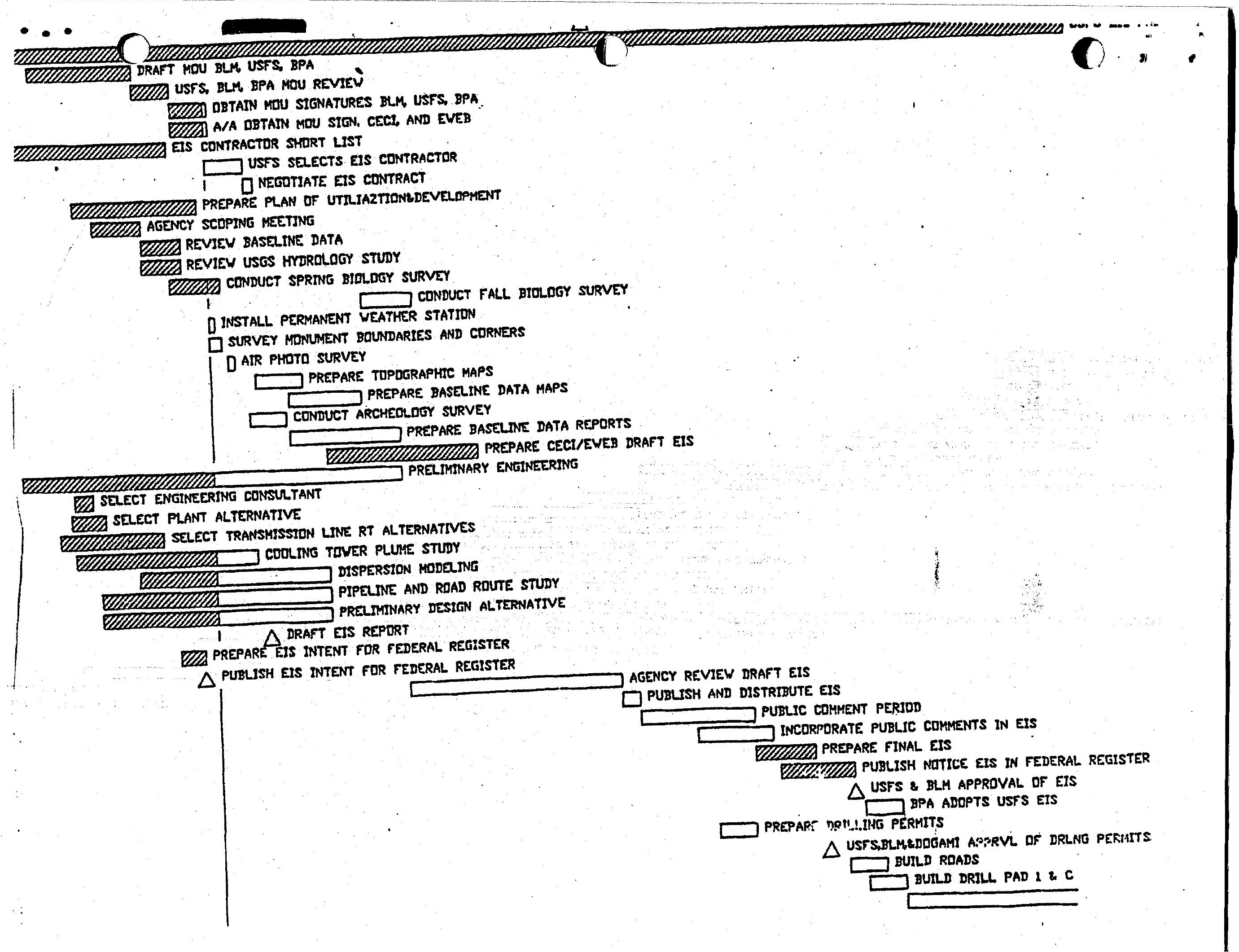


....

WINTER DRILLING BREAK

DRTLL COREHOLE 1

$\square$ DRILL COREHOLE 2

TIIIIIS DRILL PRODUCTION TEST 1

$\square$ 3ULLD DRTLL PAD 2 \& PAD 3 PODCTIDN VELLS 2 \& 3

VIIIIIIIIIIII DRRL PRDDUETION WELLS 2 \&ELS 1 \& \& 3

DIIIIIIIIS TEST PRDDUCTION VELLS IT REPDRT

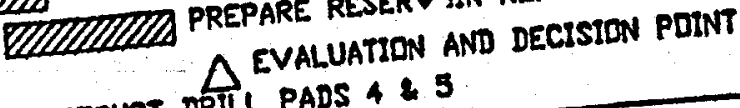

CONSTRUET DRILL PADS A \&

PREPARE RESERVUIR REPDRTS
DF RESERVE

$\triangle$ CONFIRMATION DF $10 \mathrm{MW}$ - $60 \mathrm{MW}$ RESTRVE 